\title{
Fotografias feitas a mãos de escrita: uma poética do infravisual na Educação ${ }^{1}$
}

\author{
Fotografías hechas a manos de \\ escritura: una poética de 10 \\ infravisual en la Educación
}

Steph Lotus ${ }^{2}$

Máximo Daniel Lamela Adó ${ }^{3}$

1 Esta pesquisa foi realizada com apoio da Coordenação de Aperfeiçoamento de Pessoal de Nível Superior - Brasil (CAPES) - Código de Financiamento 001

${ }^{2}$ Atua como artista Visual e fotógrafa, pesquisa Educação no campo das poéticas visuais. Mestranda em Educação na linha de pesquisa Filosofias da Diferença e Educação da Faculdade de Educação (UFRGS). Licenciada em Artes Visuais no Instituto de Artes (UFRGS).

Lattes: http://lattes.cnpq.br/6699575165075694

E-mail: stephannylotus@gmail.com

3 Professor Adjunto no Departamento de Ensino e Currículo da Faculdade de Educação e Professor Permanente no Programa de Pós-Graduação e Educação da Universidade Federal do Rio Grande do Sul - UFRGS. Coordenador o AtEdPo - Ateliê de Educação Potencial. Doutor em Educação (UFRGS). Mestre e Teoria Literária (UFSC) e Licenciado em Ciências Sociais (UFSC).

Lattes: http://lattes.cnpq.br/5778480459612105

E-mail: maximo.lamela@ufrgs.br 


\section{Resumo}

O texto aborda conceitos e materiais trabalhados em aula a partir de uma proposta de estágio de docência em uma disciplina voltada para as licenciaturas na Universidade Federal do Rio Grande do Sul. A proposta se vale de exercícios de escrita e trabalha um viés poético, a partir de um visual fotográfico. Procura-se entrar na arte literária com o fazer da fotografia para escrever com o ínfimo, como um fator mínimo, o infra de um cotidiano visual da docência. Ao tomar esse fazer em uma concepção com o fotográfico, teríamos algo como um infravisual, uma poética. Compreende-se com Barthes (2013) que a escrita envolve um gesto manual e esse gesto ele o chama de escripção, se dá na prática de uma escrita manu-corporal. E, com Valéry (2018) e Adó (2013), como uma ação transformadora do espírito. Por fim, e por vias fotográficas, afirma-se o trabalho docente ao especular sobre o fazer artístico da escritora Virginia Woolf. Nisso, observa-se uma potência que pode, (ao extrair desses estudos recursos literários) viabilizar a produção de uma escrita em Educação que seja, ela mesma, de tropo fotográfico. Ou seja, um pensamento fotográfico que se produz por uma poética do infravisual.

\section{Palavras-chave}

Docência; escripção; fotografia; infravisual; poética.

\section{Resumen}

El texto trata de conceptos y materiales trabajados en aula a partir de una propuesta de prácticas preparatorias para la docencia en una disciplina direccionada para las licenciaturas de la Universidade Federal do Rio Grande do Sul. La propuesta se vale de ejercicios de escritura y trabaja por una orientación poética, a partir de un visual fotográfico. Se busca entrar en el arte literario con el hacer de la fotografía para escribir con lo ínfimo, como un factor mínimo, lo infra del cotidiano visual en la docencia. Al tomar ese hacer en una concepción con lo fotográfico tendríamos algo como un infravisual, una poética. Se comprende, con Barthes (2013) que la escritura conlleva un gesto manual y ese gesto el lo llama de scripción; una práctica de escritura manu-corporal. Y, con Valéry (2018) y Adó (2013), como una acción transformadora del espíritu. Por fin, y por vías fotográficas, se afirma el trabajo docente al especular sobre el hacer artístico de la escritora Virginia Woolf. En eso, se observa una potencia que puede (al extraer de esos estudios recursos literarios) viabilizar la producción de una escritura en Educación que sea, ella misma, de tropo fotográfico. O sea, un pensamiento fotográfico que se produce por una poética de lo infravisual.

\section{Palabras Clave}

Docencia; scripción; fotografía; infravisual; poética.

ISSN: 2447-1267 


\section{Uma escrita fotográfica na Educação}

Este texto apresenta uma escrita com procedimentos que pensam a formação docente por meio de uma dimensão poética. Nesse sentido, relaciona certa noção de apropriação como o agenciamento de encontros que visam envolver uma mistura de linguagens e códigos em suas produções. A ideia de escrita fotográfica que tratamos neste texto experimenta uma docência, superposta à pesquisa, com atenção às unidades analíticas: aula, método e educador, naquilo que concerne às relações de mistura com e entre fotografia, literatura e educação. Com isso, pretende dar corpo a um pensamento que explore a educação em suas potências, experimentando situá-la nas fronteiras dessas práticas artísticas e, deste modo, nesse artefazer, agir em sua transgressão por meio de novas situações didáticas. (ADÓ, 2016;2013). Com relação a noção de apropriação, podemos afirmar uma afinidade diretamente justaposta ao processo de estudos especulativos na produção poética de Virginia Woolf, em sua potência fotográfica.

Estabelece, assim, o intuito de engendrar novas relações na tarefa de produzir aulas, entendendo a aula como "um lugar de avizinhamentos, um espaço de ruptura e transgressão pela inserção do descontínuo e da proliferação de signos provindos de lugares múltiplos" (ADÓ, 2019). Com isso, intui-se a produção de diferença autoral, envolvendo o pensar docente em sua complexidade contemporânea. Dessa forma, a fim de dilatar o conceito de docência para uma perspectiva fotográfica via abordagem de exercícios de escrita, viabiliza um processo de transformação de si, de produção de alteridade. Tais exercícios, como a escrita no dizer de uma latência literária, emergem como uma experiência antes da experiência e que ressoam como uma vivência docente na disciplina ofertada para cursos de licenciatura, junto aos exercícios propostos pelo projeto de estágio docente como parte integrante de uma pesquisa de mestrado.

Para tanto, propõe o trabalho de um pensamento fotográfico fomentado no exercício de escriler (CORAZZA, 2013) uma vida ficcional, ou melhor, procura trabalhar um pensamento fotográfico no próprio exercício da literatura usando a escrita como arte, e não como um método de autoexpressão, como nos alerta Woolf(2014), compreendendo literatura como "[...] o grafo complexo das pegadas de uma prática: a prática de escrever." (BARTHES, 2013, p. 17)

Nesse contexto, apresenta-se exercícios experimentais, traduzidos aqui como uma dobra de pensamento em planos estritamente fotográficos. Assim, pode-se dizer de uma vivência poética docente, trazendo a noção de poética como pura e simples ação do fazer (o poïen), das artes e de ação transformadora para além de uma autoexpressão. Ou, simplesmente, tentativas de traduzir, na materialidade da escrita, gestos, potências e efeitos de uma aula. (VALÉRY,2018; ADÓ,2013; WOOLF,2014)

Articulando, portanto, o gesto da escrita exercitado com a arte fotográfica, desenvolve-se um ato docente, como uma câmera fotográfica acionada sobre o tripé: aula, método e educador. Se a fotografia é regida, em sua superfície, por um referente externo, (BARTHES, 1984) ao se misturar com um fazer literário feito à mão, trata sua 
potência visual de modo a criar um novo índice de real que pode ser lido como poesia fotográfica e/ou como produção de alteridade de um real visual no cotidiano da Educação. Por essas vias, a Educação se afirma "[...]por aquilo que pode em ato, admitindo que sua constituição seja processual e constante." (ADÓ, 2016, p. 7)

\section{Para pensar uma docência poética: um trabalho escriptual}

Em 1973, Roland Barthes escreve para o instituto acadêmico de Roma um dossiê raro a respeito do fazer manual da escrita. Em fragmentos, o texto trata sobre o conceito de escritura, já muito trabalhado pelo autor, porém, afastando a ideia de estilo literário para aproximar a exploração da escrita à ideia de um fazer do corpo. Para isso, o autor escreve quanto a importância do saber do corpo: o saber fisiológico do corpo é muito mais do que sua própria fisiologia (BARTHES, 2002). Quer dizer que, como uma volta sobre si mesmo, Barthes critica seu próprio trabalho como escritorprofessor ao dizer que usou metaforicamente esse termo [escritura] nos seus escritos dos últimos vinte anos, não atingindo a palavra em sua relação manu-corporal.

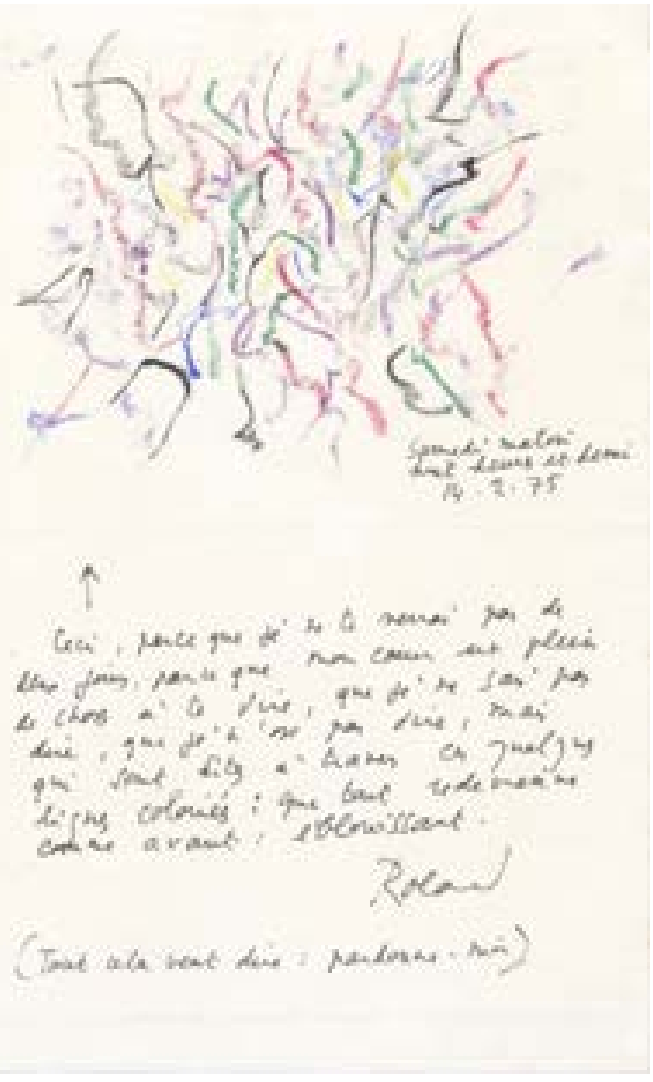

Fig. 1. Escripção Roland Barthes, disponível em: https://piaui.folha.uol.com.br/um-fragmento-dodiscurso-amoroso-de-barthes/. Acesso em 10.02.2020

Para Barthes a escripção é o ato muscular de escrever ao traçar as letras (BARTHES,

1 Pela tradução para o português brasileiro, no livro: BARTHES, R. O grão da voz. Tradução de Mário Laranjeira. São Paulo: Martins Fontes, 2004. 
2002). A escritura manuscrita que se faz no apertar, no acariciar uma superfície, no desenhar formas rítmicas. Como uma retomada para o corpo A escripção foca, por tanto, no gestual, nas relações entre gesto escritural e o corpo do escritor-leitor. Barthes afirma conhecer de sua escritura, somente aquilo que conhece de seu corpo, uma cinestesia, a experiência de uma pressão, de uma pulsão, de um deslizamento, de um ritmo. Trata-se de uma produção e não de um produto, um gozo e não uma inteligibilidade (BARTHES, 2002). Seria um modo de fazer da escrita uma produção em oposição à escrita como produto. Um estado vivo da inserção do corpo na letra escrita. O lugar onde a letra manifesta sua natureza manual, artesanal, operatória, corporal e porque não dizer, selvagem (BARTHES, 2002).

Tensionando a atividade da escritura em suas relações entre o gesto escritural e o corpo como afetações à sua sensibilidade intelectual, Barthes diz se efetuar "Um acontecimento escritural" (BARTHES, 2002, p. 125). Tal acontecimento se exibe no ato próprio de um cotidiano da docência, do dia a dia seja de um estudante, seja de um educador. Ou seja, colocar o peso do corpo no gesto de escrever sobre o papel faz parte da tarefa da pesquisa acadêmica intrínseca no ato docente.

Pensando assim, de forma parecida podemos focalizar a fotografia, ou melhor o fazer fotográfico inserido no campo da Educação? Talvez! Se consideramos o modo acelerado e ilimitado em que produzimos fotografias no cotidiano podemos especular a sua banalização, ou seja, uma atenção maior ao produto que a sua produção. Assim, um cuidado com o fazer fotográfico, a sua manualidade, procuraria chamar atenção para o gesto, esse fazer com o corpo e, ainda nesse sentido, um fazer espiritual. Especula-se que de algum modo o fazer fotográfico devolveria à escrita, também como imagem, a relação superposta entre corpo-espírito.

Para isso reivindicamos o termo espírito em sua acepção valeryana, ou seja, como intelecto. Como uma consciência de si ao modo de uma vontade de potência intelectual. Uma inteligência capaz de analisar o mundo exterior e o interior. (PIMENTEL, 2008).

Com objetivo de entrecruzar com Barthes e Valéry um fazer que se produz espiritualmente, uma poética. Como pretexto ou ilusão literária: um trabalho escriptual, como um trabalho do intelecto: uma escrita do fazer, do verbo.(VALÉRY, 1979) Um ato escriptual, é um ato que se projeta para além do corpo como uma imagem paradisíaca: "um cuerpo que levanta el vuelo" (BARTHES, 2002, p. 123) Por isso, pode-se afirmar o ato escritural como um ato escriptual, na invenção de um neologismo que dê conta de expressar o trabalho da escripção. Bem como apresenta Barthes, a escrita em oposição a uma estrutura linguística, seguindo a favor de uma escripção, expressada aqui como uma escrita do espírito.

Com isso, pergunta-se: podemos, a partir da escripção, perspectivar uma didática fotográfica que coloque em primeiro plano a atividade do espírito na formação docente?

Tal questionamento pode ser fragmentado em perguntas que, longe de serem respondidas, colocam-se como pequenos enquadramentos a fim de desenvolver 
matéria para pensar o fotográfico ${ }^{2}$ em prol de um ato escriptual como atividade de potência do intelecto. São elas: para onde apontar o olhar, ou como enquadrar uma escripção? Uma docência que trata o pensamento como fotográfico, pode-se dizer articuladora de uma didática que seja também fotográfica?

\section{Escripção fotográfica com Virginia Woolf}

[...] imediatamente vemos - mas o olho da mente apenas por obséquio é um olho; é um nervo que ouve e cheira, que transmite frio e calor, que está ligado ao cérebro e estimula a mente a discriminar e a especular. (WOOLF, 2017b, p. 102)

Por uma questão de brevidade, podemos fincar nossos olhos afirmando ver uma coisa e no momento seguinte, essa coisa pode se tornar, diante nossos olhos, uma outra coisa. Assim também, em um mundo rodeando por imagens, um mundo imagético (visual), pouco se explora sobre a relação estreita que a escritora Virgínia Woolf manteve com a fotografia, mais ainda: de como ela usou dessa arte como método de escrita. Sabemos do peso de seus romances e contos, por exemplo, mas, ao entrar em contato com esses feitos, é da ordem do comum importar-se mais com sua vida e obra do que com os seus processos artísticos de criação na escrita.

Dessa forma, interessa estudar a sua poética, seus atos sensíveis de composição de seus livros, sem precisar acessar sua biografia. Dito isso, sugere-se ler Woolf como um livro de poesia visual e porque não dizer de poesia fotográfica. Suas escritas de tropo fotográfico são estudadas com objetivo de, a partir delas, exercitar a escrileitura e a escripção. Bem como podemos experimentar, a título de exemplo, através do conto: A marca na parede.

A escritora vê-lê-escreve seu mundo sensível como uma poesia transmodal (HUMM, 2017), que se faz ao mesmo tempo visual e fotográfica. Visual porque se apropria de temas das artes visuais para escrever literatura; fotográfica porque descreve a partir de fotografias e da própria visão de seus olhos, estados de alteridades do real. Virginia Woolf nos ensina acerca da arte fotográfica no fazer literário.

Vale lembrar que Woolf era sobrinha neta de Julia Margaret Cameron (18151879), fotógrafa que fez parte do movimento pictorialista, o momento em que acontece uma virada pictórica da fotografia (BRIZUELA, 2014), indício menos evidente na américa latina com essa nomeação, mas que se lastrou por diversos continentes. Com importância, abriu espaço artístico para atuação de mulheres, Cameron foi uma delas que muito íntima da literatura era próxima de escritores, a exemplo de Charles Lutwidge Dodgson(1832-1898), mais conhecido pelo seu pseudônimo Lewis Carroll, com quem divide com Cameron a fama de fotografar Alice Pleasance

2 Philippe Dubois (2012) Usa o termo em um sentido mais amplo do que quando se fala de poético para se referir à poesia, ou seja, a fotografia como dispositivo teórico. 
Liddell(1852-1934) para quem ele dedica a obra Alice no País das maravilhas de 1865. Para fins contextuais e não biográficos, vale observar que essa elite literária e fotográfica, parece anunciar um fazer das artes como processo de mistura para um conhecimento intelectual. É nesse viés que interessa para a Educação. Ou seja, como, a partir do trabalho de escritores como a Virginia Woolf, pensar fotograficamente exercícios de aula que contemplem um fazer literário?

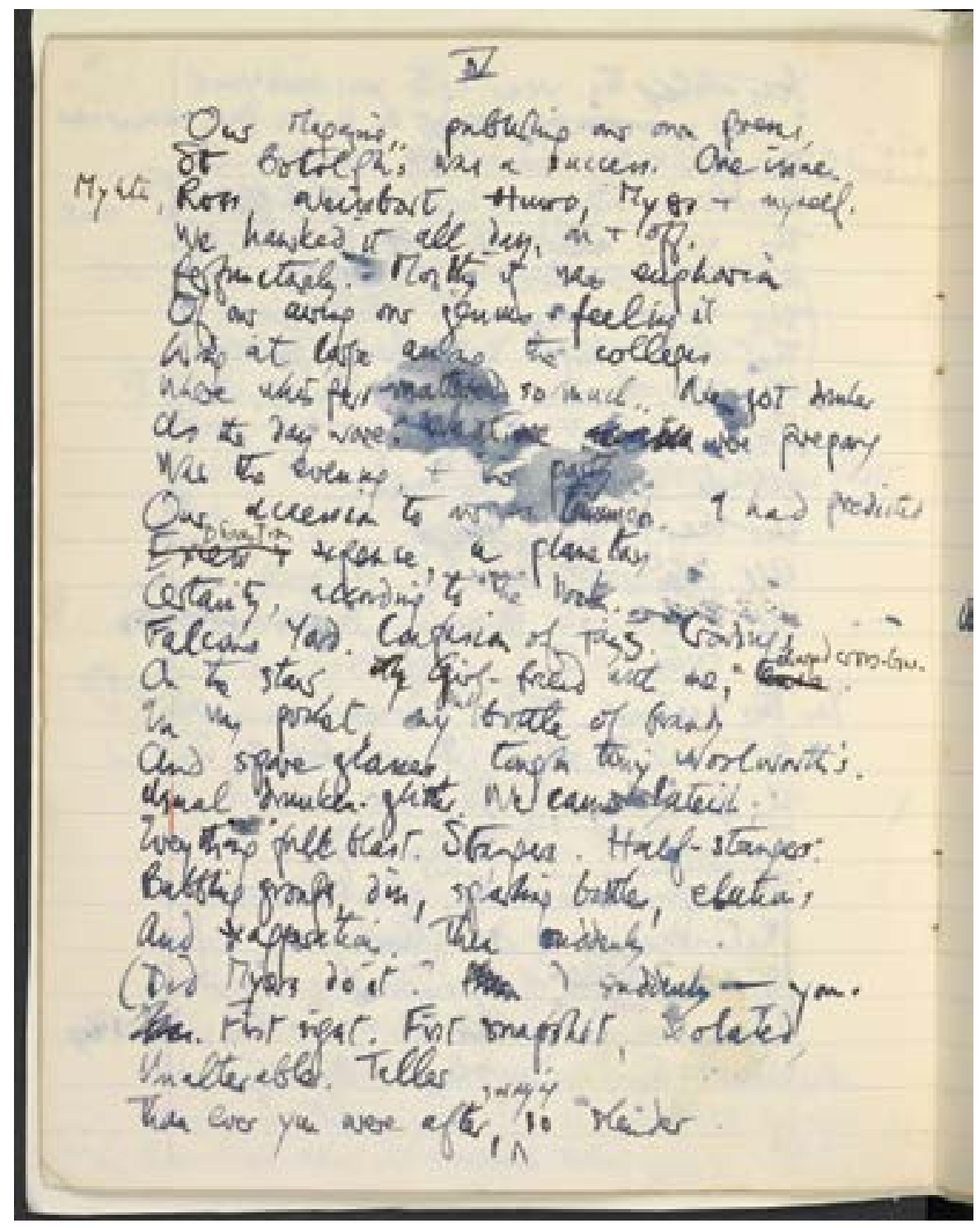

Fig. 2. Escripção Virgínia Woolf, disponível em:

https://blogs.bl.uk/english-and-drama/diaries/. Acesso em 13.02.2020

\section{Exercício Infravisual: escrita fotográfica de observação}

Para desbravar uma escrita em aula, faremos como em um exercício tradicional de desenho de observação em que se traça com a presença de um modelo vivo 
diante nossas lentes oculares. Assim, em uma de-scripção (BARTHES, 2002) em notas, descreve-se em aspectos fotográficos, como se pudéssemos fotografar apenas com palavras ou como se pudéssemos desconstruir uma paisagem/retrato visual.

Suponha que o espelho rache, a imagem desapareça, e a figura romântica, com todo o verde das profundezas das florestas à sua volta, não esteja mais ali, restando apenas aquela carapaça de pessoa que é vista pelos outros. (WOOLF, 2017a, p. 19)

Com aspectos do fotográfico, traduzidos para uma escrita por meio da observação do visual, um educador pode produzir escrita poética ou fotográfica? Como efeito de comédia intelectual, um modo de escrever que:

[...] trava ações ordinárias e de escrituras do mundo habitual em relação às ações do Educador para com ele mesmo. Faz anotações do vulgar, do ínfimo, do mínimo no cotidiano, tendo o cotidiano como esse lugar em que se pode desencadear uma prática em que a vida possa ser traduzida como processo de criação. Pergunta-se, antes de qualquer coisa, quantos e quais gestos são necessários para escrever a palavra Educador; tudo isso com o intuito de estar impregnada das e nas formas desse espírito, para descrevê-lo como matéria própria a ser descrita. (ADÓ, 2013, p. 35)

Para escrever com um ínfimo, com um fator mínimo de um cotidiano visual docente; para enquadrar uma escripção, pode ser necessário especular o que se tem de infra se tratando de um enquadramento observado. A partir do que Georges Perec (1936-1982) chamou de infraordinário; e do que Marcel Duchamp (1887-1968) chamou de inframince, em uma concepção com o fotográfico, teríamos algo como um infravisual, uma poética. Para entrar na arte literária com fazer da fotografia seria como descrever, por exemplo, uma sobreposição de sombras que se projeta diante nossos olhos, mas que, na escrita, pode acentua-se mais como uma sensação e menos com a percepção do visual. Ou seja, sensações que mesmo estando perante nossos olhos, necessitam de tempo de observação para acessar um modo de ver. Quer dizer que um fator fotográfico se dá na íntima relação com a observação de um real visual. Ou seja, uma simples descrição de algumas sombras, pode se tornar matéria de uma escrita fotográfica.

Essa mistura, de uma arte com outra [fotográfica e literária], coloca em vista uma maneira de pensar a escrita para além do que estamos acostumados a fazer, como nos ensina Virginia Woolf no criar fotograficamente: "Assim, penso agora no fogo; na firme película de luz amarela sobre a página de meu livro; nos três crisântemos do jarro redondo de vidro em cima do console da lareira. (WOOLF, 2017a, p. 9)

Na descrição de uma cena limitada como fotográfica, anotar elementos técnicos de uma fotografia, tais como: enquadramentos em retrato, paisagem, oval ou quadrado. Luz[es]: direta ou indireta, artificiais, solar, difusa, dura, mista, contraluz, silhueta, meia luz; luz de recorte; luz de janela. Sombras, duras e difusas, coloridas, projetadas. Foco; granulação; linhas de perspectivas; ângulos, distorções, camadas/ planos; profundidade de campo; nuances; tons. Cores diversas; pretos e brancos; 
saturações, profundidade e brilho, matizes, gama, realces, relevos, texturas, reflexos, molduras. Efeitos produzidos com objetos ópticos, tais como: lentes diversas, filtros coloridos, cristais, espelhos, vidros etc.

Vejamos algumas das notas produzidas em aula transcritas como um texto corrido, seguidas de registros fotográficos dessas escripções: ${ }^{3}$

Um efeito de luz sobre o rosto, o claro de um lado realça o vermelho de outro. Há vermelho sem o claro? aumento/expansão e diminuição/redução da perspectiva com a mudança de espaço/lente. Há realidade ou perspectiva? Um prisma como campo de possibilidades para um mesmo frame. Lados, cores, arco-íris, opaco, parede. O rosto refletido em si mesmo. Tem luz vinda do lado esquerdo, estou ao lado contrário à luz, vejo somente uma sombra ao lado direito do seu rosto. Por dentro de uma janela indiscreta, o jeito em que os olhos se movimentam ao passo em que todos na sala a enxergam, a enxergam? (janela indiscreta) $O$ furo no queixo, que eu via, agora se mexe, vejo somente a sombra do rosto (sob a sombra) Com um filme fotográfico tudo muda, a lente muda o rosto parece mais pesado (o rosto). Cabelo cor de Sol se pondo, cor quente. Camadas de cores misturadas. Visto meu olhar com uma lente caleidoscópica.

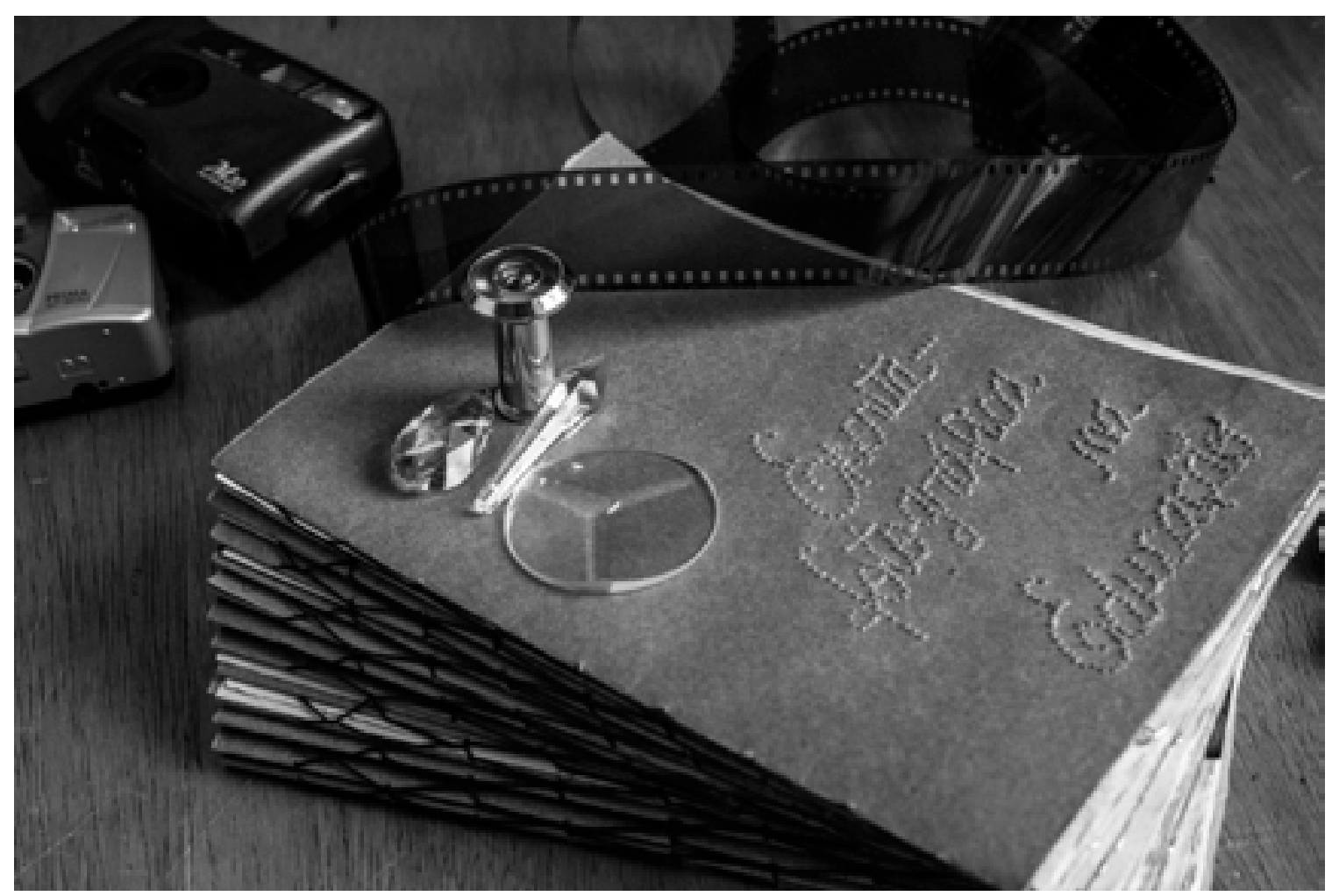

Fig. 3. Registro fotográfico I - caderno de escripções 2019, arquivo pessoal

\footnotetext{
3 Exercitando a ideia de descrever fotograficamente um modelo vivo durante a aula produzimos algumas escripções, organizadas posteriormente em um caderno costurado à mão conforme registros fotográficos que seguem o texto. Para fins de exposição, escolhemos algumas escripções de autoria diversa: André Cristo, Beatriz Martignori, Cristian Silveira, Elza Nascimento, Gabriela Schwerz Machado, João Lentino, Maria Galant, Vitória Munhóz.
} 
Chão de madeira, meia torta, língua torta do sapato. Difícil capturar um frame que se movimenta. A imagem se repete cerca de vinte vezes. $O$ enquadramento da pessoa se dá com metade do rosto como se enxerga "natural" e a outra metade através de uma espécie de pirâmide de vidro com estrutura metálica dourada. De uma maneira que uma das esferas triangulares cobre meia face. Em decorrência da espessura do vidro, a pele que já é pálida, fica ainda mais. O tom dos cabelos se altera para nuances mais claros. Meu posicionamento em relação a ela é como se comparado à um relógio: ela nas $12 \mathrm{~h}$ e eu às $4 \mathrm{~h}$. Através de uma lente com texturas que remetem a um diamante, a face se multiplica em, aproximadamente 15 réplicas. O rosto que não aparece por completo, corta em parte o topo da cabeça. Mostrando principalmente o queixo que tem um risquinho no centro na diagonal; a boca, a maçã do rosto dando um certo ar de tédio pela falta de reação. Através de uma câmera fotográfica de rolo de filme,

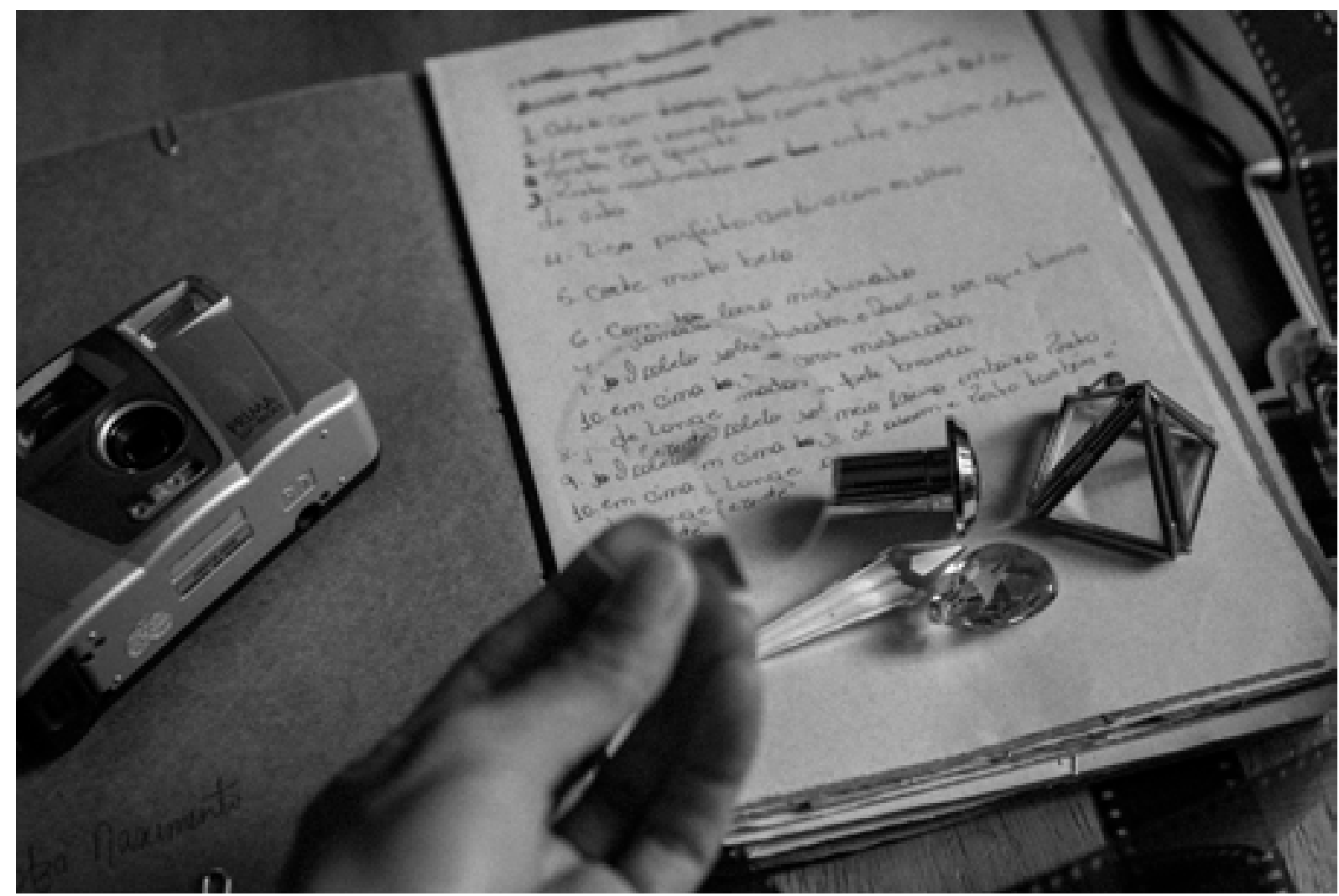

Fig. 4. Registro fotográfico II - caderno de escripções 2019, arquivo pessoal

a modelo está viva num tom roxo. Toda atmosfera da imagem ficou roxeada. Talvez um pouco lilás até ou roxo super claro. Minha posição agora: eu em 10h e ela 12h. Devido uma luz forte que vem da janela, uma luz sobre ela também está forte. A câmera, por ser antiga dá reflexo em dois pontos: $1^{\circ}$ como um círculo próximo ao peito e $2^{\circ}$ como duas listas em formato de moldura no canto inferior da lateral esquerda. Reflexo bem definido em amarelo. Através de uma lente olho de peixe, a imagem se 
alastra, aumenta. A visão é ampliada. É possível enxergar todo corpo. Os pés cruzados, uma mão sobre a classe e a outra repousa na perna. Ela parece bem pequena daqui. Sensação de que metade da sala de aula cabe em uma lente. Olhando através de o que parece ser uma tampa: a modelo se divide em pelo menos três partes. A cabeça foi coberta de uma maneira que apenas as pontas dos cabelos na frente dos ombros apareçam. Reflexos difusos do olhar, levemente sorridente, tons cinzas, linhas curvas, recorte circular de onde está a imagem. Um fundo de garrafa existe, do lado direito uma linha reta obscura que escapa aos olhos. Recorte dentro do recorte da imagem. Encadeamento de padrões circulares e espiralescos para reforçar a leitura cíclica. O olho, a sobrancelha, as marcas do rosto, o cabelo, a moldura interna e suas pétalas. A luz da chuva que não cai e a cor do mormaço. O recorte do que aparece no rosto. Olhos de saudade feliz. Olhando através de um cristal multifacetado lilás, a imagem se desfaz, as cores parecem se dividir nas cores do arco-íris (refração). Fica difícil identificar objetos, elementos da cena se fundem na imagem que tento focar. Vermelho, amarelo, verde, cinza/branco, azul, roxo.

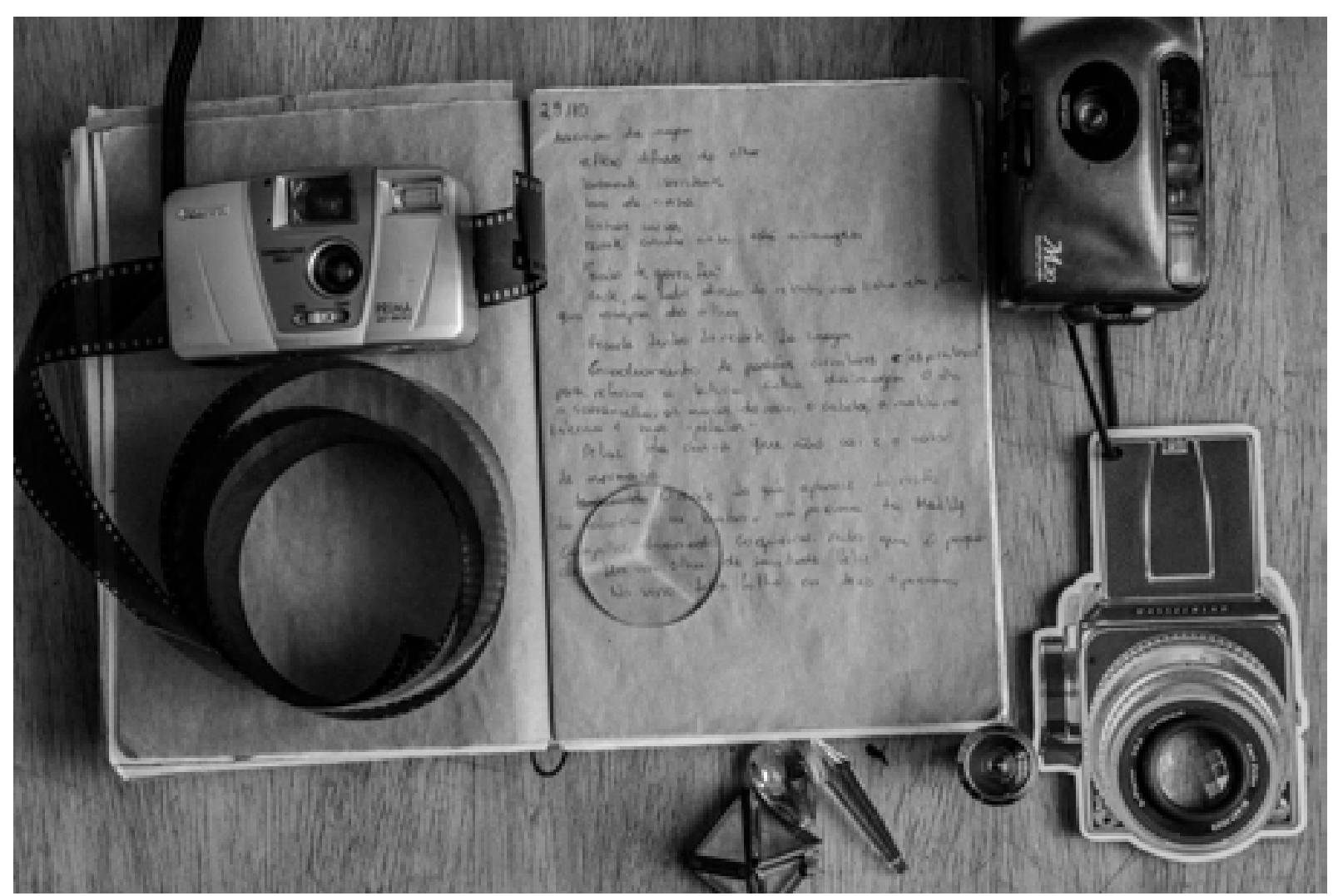

Fig. 5. Registro fotográfico III - caderno de escripções 2019, arquivo pessoal

Um olho meu está fechado (esquerdo) o efeito é diferente. As extremidades ficam coloridas. A imagem se repete e se multiplica. As dobras, tudo tem profundidade, tudo tem arco-íris. Vejo da cintura para cima e foco no canto direito da imagem para poder observar a figura (que se repete, mas em 
frames diferentes, como se eu escolhesse um frame do frame). Fora do arco-íris as cores parecem "normais" como se não houvesse nada a frente de meus olhos.

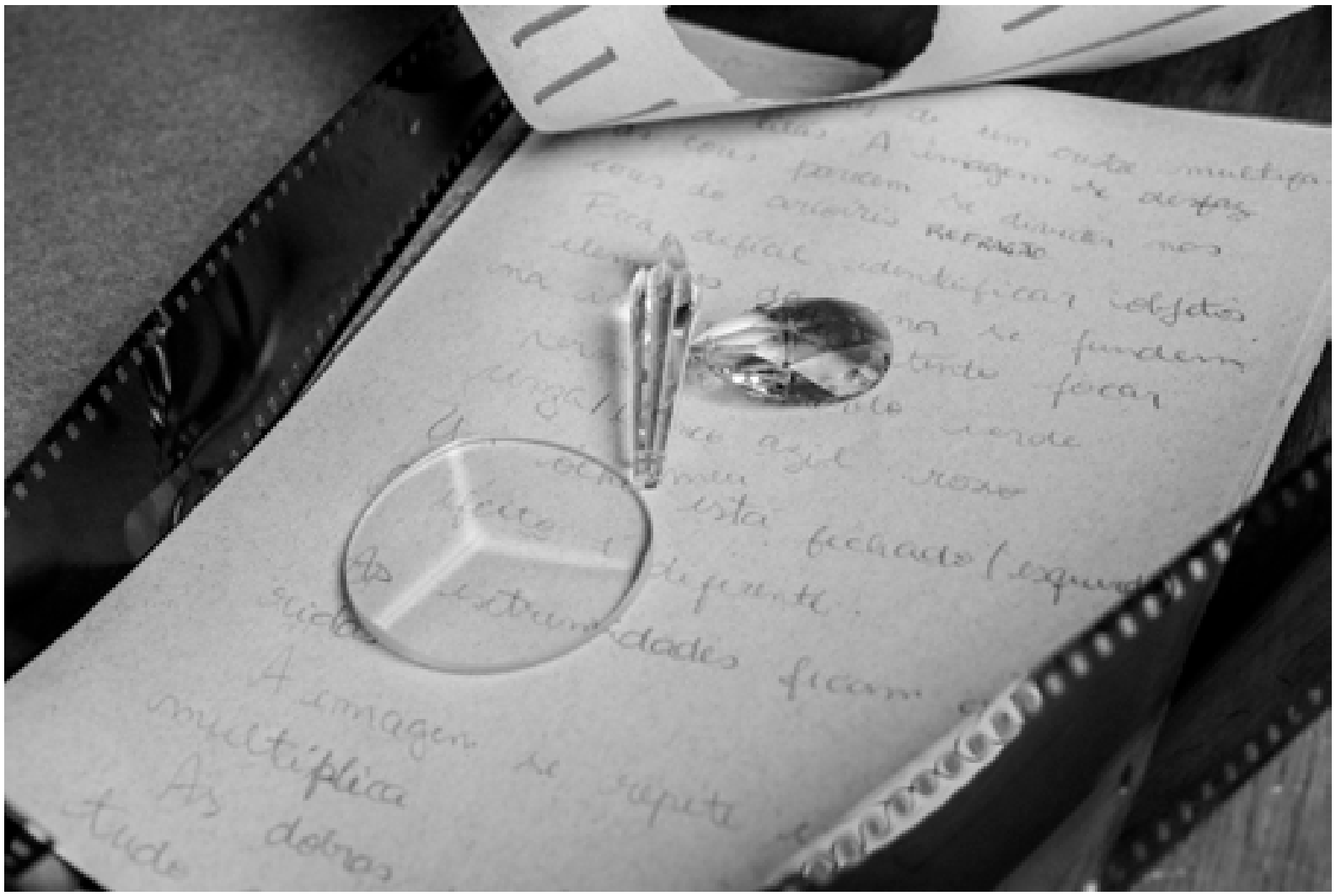

Fig. 6. Registro fotográfico IV - caderno de escripções 2019, arquivo pessoal

Na trama de um texto escritural, os pensamentos fotográficos acima se projetam como o próprio aflorar da língua, transparecendo o limite entre literatura, escritura ou texto. (BARTHES, 2013) Ao analisar esse material poético, podemos sugerir que temos em mãos um método? Tratando-se de método, Barthes afirma que:

[...] se portanto o método intervém a título de procedimento sistemático, não pode ser um método heurístico, que visaria a produzir deciframentos e apresentar resultados. O método não pode ter por objeto senão a própria linguagem, à medida que ele luta para baldar todo discurso que pega: e por isso é justo dizer que esse método é também ele uma ficção: proposta já avançada por Mallarmé, quando pensava em preparar uma tese de linguística: "Todo método é ficção. A linguagem apareceu-lhe como instrumento da ficção: ele seguirá o método da linguagem: a linguagem se refletindo" (BARTHES, 2013, p.44. grifo do autor)

Essa linguagem que reflete a si mesma, neste estudo, diz de um pensamento fotográfico em decorrência de uma didática fotográfica, uma didática da invenção (CORAZZA, 2013). Como se pudéssemos agir fotograficamente com o espírito na formação docente. 


\title{
Considerações finais: a fotografia fora de si
}

\begin{abstract}
A proposta de uma fotografia sem fotografia libera o meio daquilo que o caracterizou, ontologicamente, desde os seus múltiplos inícios no século XIX: a indexicalidade. (BRIZUELA, 2014, p. 187)
\end{abstract}

Outro estudo que vai ao encontro do tema fotografia e literatura, pode ser lido no livro Depois da fotografia: uma literatura fora de si. Nesse livro a professora de literatura, cinema e artes visuais Natália Brizuela, afirma que nos anos 90 na crítica literária e nos estudos culturais, acontece algo que estava sendo verificado e muitas vezes expresso como a viragem para o visual. (BRIZUELA, 2014) Apontando para o fazer da fotografia na literatura, ao trazer a questão da indexicalidade das imagens, a autora questiona: o que acontece quando a literatura toca a fotografia? Soando como uma inversão dialética, a pergunta de Brizuela vai pautar um território extenso nessa quebra de limites entre arte fotográfica e arte literária. Onde e como acontecem as misturas dessas artes? Através de que gestos escritores e artistas experimentaram, ou seja, de que maneiras manusearam essas artes?

Após o surgimento da fotografia a literatura está fora de si (BRIZUELA, 2014) - eis sua tese de propósito duplo: por um lado explora a fissura que deixará a fotografia infiltrar-se no campo literário, e por outro a literatura no campo fotográfico.

Apesar de se debruçar sobre os aspectos fotográficos nas obras de vários escritores como: Juan Carlos Onetti (1909-1994) e Julio Cortázar (1914-1984), sua pesquisa tem foco nítido na obra do escritor mexicano Mario Bellatin, pois é ele quem, para Brizuela, vai misturar essas artes a ponto de produzir alteridade dentro do próprio campo: na arte de tirar fotografias sem fotografar - a fotografia liberta do índice passa a ser objeto de criação (BRIZUELA, 2014).

A literatura fora de si, segundo a autora, expressa uma abertura poética que na obra de Bellatin, direciona o exercício da escrita como arte. "A prática literária de Mário Bellatin é a da arte conceitual" (BRIZUELA, 2014, p. 193) A incorporação do fotográfico como meio para atividade da escrita. Depois da fotografia, [não do seu surgimento no mundo, mas sim da apropriação dessa arte por artistas escritores] a literatura está fora de si.

Mas, como nos apropriar desse estudo na atuação docente? Ou melhor, como podemos transpor essa ideia para trabalhar fotograficamente em aula? Aproximar esse pensar a uma poética do infravisual na Educação, por meio de uma escrita fomentada por um pensamento fotográfico, seria uma via inversa ao que questionou Brizuela, algo como: como acontece quando a fotografia toca a arte literária? Ocasionando algo parecido com uma ficção dentro de outra ficção e não somente a fotografia que toca um real, mesmo que esse real seja compreendido como ficcional, como pode ser lido no estudo teórico e na semiótica barthesiana (BARTHES, 1984). Assim, pode-se afirmar que só a ficção tem a força de saber algo, com certeza. A certeza não é a certeza propiciada por uma iluminação, por uma explicação detalhada. É a certeza que sabe que não se pode saber. Assim, fazer de tudo ficção, seria um efeito de linguagem. (BRIZUELA,2014; ADÓ,2013) 
Através de obras que trabalham a escrita fotograficamente, faz-se possível uma outra indexicalidade que se afasta do "isto foi" barthesiano [tempo passado] para outra temporalidade: a do presente (BRIZUELA, 2014). Vestígios, trações indexicais que estão escritos ali não como face real do personagem, mas como signo da ficção, comenta Brizuela acerca do romance Nove noites (2002) de Bernardo de Carvalho "[...] a ficção não emerge da imaginação, mas da realidade; e a fotografia não é documento, mas ficção" (BRIZUELA, 2014, p. 27)

Com isso, ao pensar um pensamento fotográfico na Educação, misturado ao fazer literário, podemos dizer que essa fotografia feita a mãos de escrita está fora de si? Bem como tensiona Brizuela quanto à literatura?

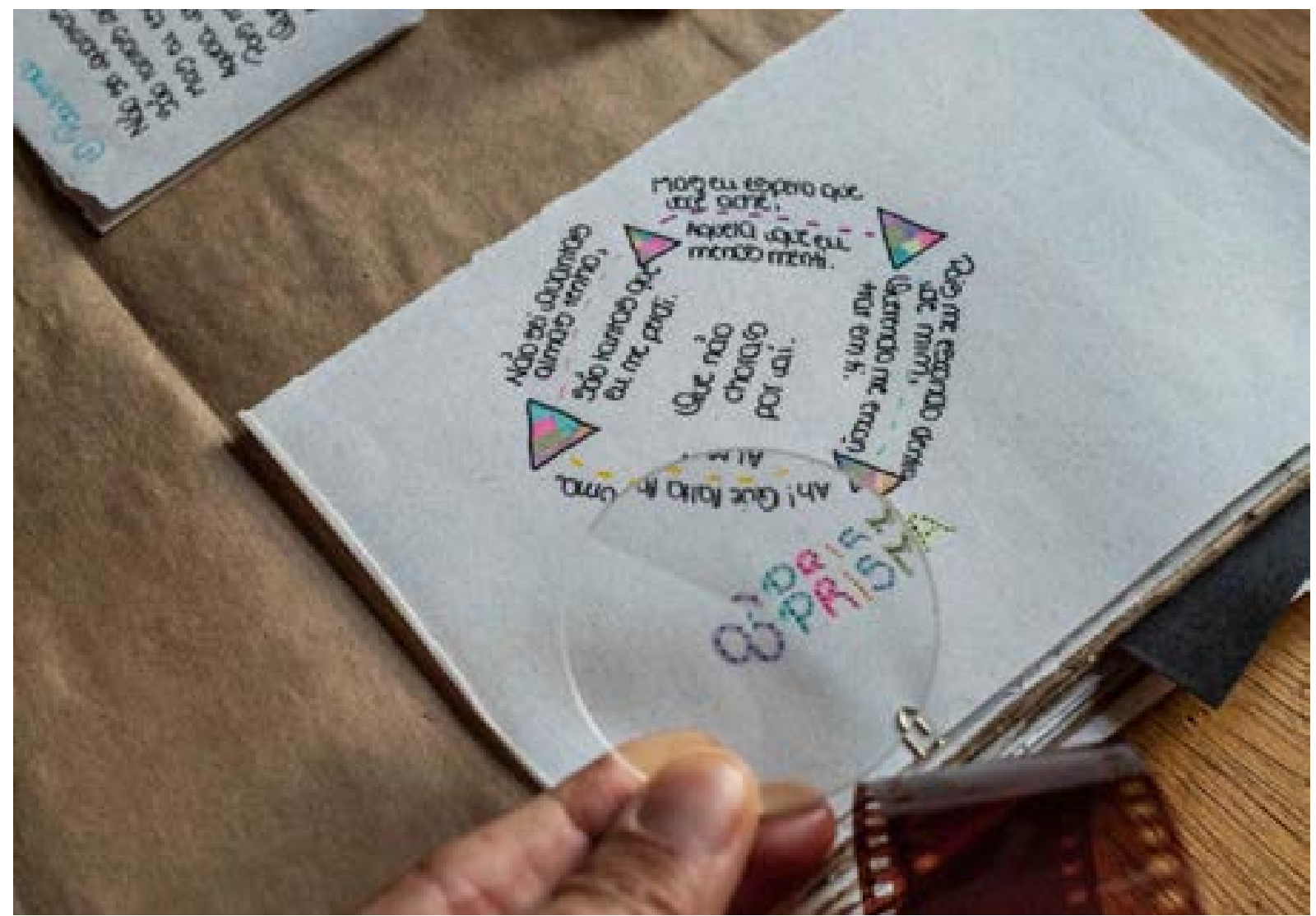

Fig. 7. Registro fotográfico V - caderno de escripções 2019, arquivo da autora

Por fim, afirma-se uma espécie de escrita poética que se produz em uma especulação foto prismática combinada à apropriação de processos artísticos [como foi o caso com Virginia Woolf], deslocados para uma espécie de método ficcional. "[...] no espetáculo de uma sala de parede branca iluminada pelo fogo, o que ganharia eu com isso? Conhecimento? Matéria para mais especulação?" (WOOLF, 2017a, p. 25) Poderíamos na fala de Woolf, com Barthes(2013), ao produzir efeito de literatura, trapacear, ouvir e ver a língua fora do poder? A escripção pode se tornar uma ação do espírito na direção de uma transformação de si? Quais efeitos podem se produzir em sala de aula, ao expor essas escripções em uma leitura coletiva? De fato, a escripção manifesta um novo imaginário que é o do pensamento em que escrever quer dizer : eu penso melhor, com mais firmeza (BARTHES, 2004, grifo do autor) Explicitar uma 
fala no grão da voz é mais do que uma tradução do imaginário do pensamento, pois a escripção tem tempo diante de si "[...] para rodar sete vezes a língua na boca[...] ao escrever o que dissemos, perdemos (ou ganhamos) tudo aquilo que separa a histeria da paranóia." (BARTHES, 2004, p. 3) escondemos tudo aquilo que nos põe em risco. Como se pode observar, diferente da escripção, "a fala é perigosa porque é imediata" (BARTHES, 2004, p. 3) ela granula todo o furta-cor de nosso imaginário; ela expõe uma espécie de sabor sublingual, o nosso modo de pensar diante do outro que, nesse texto, foi exteriorizado como um ver-ler-escrever um mundo imagético visual a partir de um fotográfico infravisual.

\section{Referências}

ADÓ, M. D. L. Educação Potencial: autocomédia do intelecto. Tese de Doutorado. Orientadora: Sandra Mara Corazza. Porto Alegre: UFRGS, 2013.

ADÓ, M. D. L. Tradução criadora na formação de professores - projeto de pesquisa. UFRGS-DEC- Departamento de ensino e currículo, 2016.

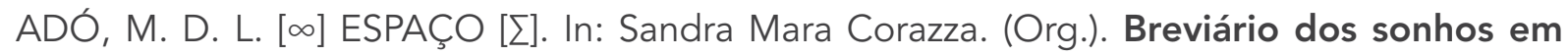
educação. 1ed.São Leopoldo: Oikos, 2019, p. 47-53.

BARTHES, R. A câmara clara: nota sobre a fotografia. Tradução de Júlio Castañon Guimarães. $7^{\mathrm{a}}$. ed. Rio de Janeiro: Nova Fronteira, 1984.

BARTHES, R. Variaciones sobre la escritura. [S.I.]: Paidos Iberica Ediciones S A, 2002.

BARTHES, R. O grão da voz. Tradução de Mário Laranjeira. São Paulo: Martins Fontes, 2004b.

BARTHES, R. Aula. Tradução de Leila Perrone-Moisés. São Paulo: Cultrix, 2013.

BARTHES, R. O prazer do texto. Tradução de J. Guinsburg. São Paulo: Perspectiva, 2015.

BARTHES, R. Roland Barthes por Roland Barthes. Tradução de Leyla Perrone-Moisés. São Paulo: Estação Liberdade, 2017.

BRIZUELA, N. Depois da fotografia: uma literatura fora de si. Tradução de Carlos Nougué. 1. ed. Rio de Janeiro: Rocco, 2014.

CORAZZA, S. M. O que se transcria em Educação? Porto alegre: UFRGS; Doisa, 2013.

DUBOIS, P. O Ato Fotográfico e Outros Ensaios. Tradução de Marina Appenzeller. Campinas: Papirus, v. 14, 2012.

DUCHAMP, M. Notas. Tradução de Dolores Díaz Vaillagou. Madrid: Tecnos, 1989. 
FRANCA-HUCHET, P. INFRA-MINCE ou um murmúrio secreto. ARJ Brasil, v. 2, n. 2, p. 40-59, jul/dez 2015.

HUMM, M. Virginia Woolf e a Fotografia. Comunicação e Sociedade, p. 375-385, 2017.

KRAUSS, R. O fotográfico. Tradução de Anne Marie Davée. Barcelona: Gustavo Gili, 2002.

PEREC, G. Aproximações do quê? ALEA, v. 12, n. 1, p. 178-180, janeiro-junho 2010.

PIMENTEL, B. Paul Valéry Estudos Filosóficos Tese (Doutorado em Filosofia) Universidade de São Paulo. São Paulo: [s.n.], 2008. 187 p.

VALÉRY, P. Introdução ao Método de Leonardo da Vinci. Tradução de José Martins Garcia. Lisboa: Arcádia, 1979.

VALÉRY, P. Variedades. Tradução de João Alexandre Barbosa. São Paulo: Iluminuras, 1991.

VALÉRY, P. Lições de Poética. Tradução de Pedro Sette-Câmara. Belo Horizonte: Âyiné, 2018.

WOOLF, V. Um teto todo seu. Tradução de Bia Nunes de Sousa. [S.I.]: Tordesilhas, 2014.

WOOLF, V. O sol e o peixe: contos. Tradução de Tomaz Tadeu. Belo Horizonte: Autêntica, 2017.

WOOLF, V. A arte da brevidade: contos. Tradução de Tomaz Tadeu. Belo Horizonte: Autêntica, 2017. 